\title{
The luminally- and vascularly-perfused small intestine as an experimental system for the study of translocation and metabolism
}

By John W. Porteous, James D. Hutchison and Valerie Undrill, Department of Biochemistry and Department of Surgery, University of Aberdeen, Aberdeen $A B 9$ I $A S$

Metabolism by intact cells involves concomitant intracellular chemical transformations of substrates via intermediary metabolites to final products and solute translocations across the cell-surface membrane: the primary substrates enter the cell from the immediate extracellular environment by one or more of several possible mechanisms located within the cell-surface membrane and some products exit from the cell by one or more of the same mechanisms. Analogous solute translocations also occur across intracellular membranes. Chemical transformations within subcellular aqueous phases or on membranes and endoskeletons, and solute translocations across membranes, together constitute the metabolism of the intact cell. Chemical transformation and solute translocation cannot be regarded as separate or separable phenomena in the intact cell, especially when 'control' of cell metabolism is under consideration (Porteous, $1983 a, b$ ). These restrictions are particularly evident in high-polarized cell systems, like those of intestinal epithelium, in which membrane translocation mechanisms and events at one part of the cell-surface membrane (the brush-border membrane) may be quite different from those at another part (the basolateral membrane of the same cell). Chemical transformations within such a cell, solute fluxes across the functionally-distinct parts of the cell-surface membrane, and net fluxes through the whole cell from one extracellular environment to another are interdependent metabolic events.

It follows that attempts to understand the metabolism of intestine in vivo should use preparations which, as near as possible, emulate the intact intestine. The vascularly- and luminally-perfused intestine has the potential to serve this purpose; it permits experimental control of the two perfusing solutions, determination of influxes and effluxes between the tissue and both perfusing solutions, and the determination of chemical transformations within the tissue.

Establishing a successful perfusion of intestine (i.e. one that has an intact vascular bed, does not exude fluid into the lumen, does not exhibit hyperaemia, epithelial necrosis or arrhythmic contractions) requires careful consideration of (a) the structure and function of the microvascular bed of the intestine in vivo, (b) the composition of the luminal and vascular perfusion media, (c) the anaesthetic and surgical procedures employed, (d) the perfusion pressures and flow-rates used, (e) the biochemical assessments and other measurements that are made. Each of these topics will be reviewed briefly. 


\section{Loction, general structure and roles of the small intestine}

In simple-stomach animals, the small intestine starts immediately distal to the stomach and ends at its junction with the ascending colon. It is traditionally divided into three functionally-distinct regions; the duodenum (next to the stomach), the jejunum and the ileum. Accessory organs which aid in the digestive and absorptive functions of the small intestine, and which connect directly with the lumen of the duodenum, are the liver (supplying surfactant bile, via the bile duct, to aid lipid digestion in the jejunum) and the exocrine pancreas (supplying, via the pancreatic duct, bicarbonate to neutralize the acid effluent from the stomach; extracellular hydrolases to continue the digestion of dietary carbohydrate and protein initiated in the mouth and stomach respectively; and hydrolases to initiate the digestion of nucleic acids and lipids). Additionally, intestinal functions, including peristaltic and arrhythmic motility, are under neural and humoral control; on the other hand, the small intestine is possibly also the site of synthesis of a wider spectrum of hormones than is any other organ in the human body (Smith \& Brunt, I98I).

The duodenum may be regarded as the intestinal compartment where the effluent from the stomach elicits pancreatic secretion of sufficient kind and quantity to titrate the gastric effluent to near neutrality, and to catalyse the hydrolytic digestions mentioned previously. The jejunum then becomes the principal site of absorption of these products of digestion of dietary carbohydrate, protein, lipid and nucleic acids from the intestinal lumen and their translocation to the vascular bed of the intestine; it is also the site of the terminal stages of intracellular digestion of some nutrients. The jejunum appears also to be the main site of absorption of inorganic ions and vitamins. Although the colon is the final site within the digestive tract of water absorption from the lumen into the circulation, the small intestine is the major site of water absorption, and the whole of the intestinal tract is involved in ion exchange between all tissues (via the circulation) and the lumen contents. If the kidneys are to be regarded as important in regulating the volume and composition of some of the total water and solution loss from the body, the intestine is equally important in regulating the volume and composition of net solution intake. The consequences of failure to absorb a sufficient proportion of the total water load on the intestine are well known, even if all the mechanisms involved in water absorption are not.

\section{The cross-sectional structure of the small intestine: muscle, connective tissue and epithelial cell components}

Intestinal tissue comprises an outermost longitudinal smooth-muscle layer, : circular smooth-muscle layer, followed by the connective tissue of the submucosa, then a thin layer (the muscularis mucosae) separating the submucosa from the inner mucosa or lamina propria. This last layer of connective tissue is normally convoluted to give irregular tongue- or finger-like protrusions or villi pointing inwards to the lumen; indentations in the mucosa are arranged around each villus 


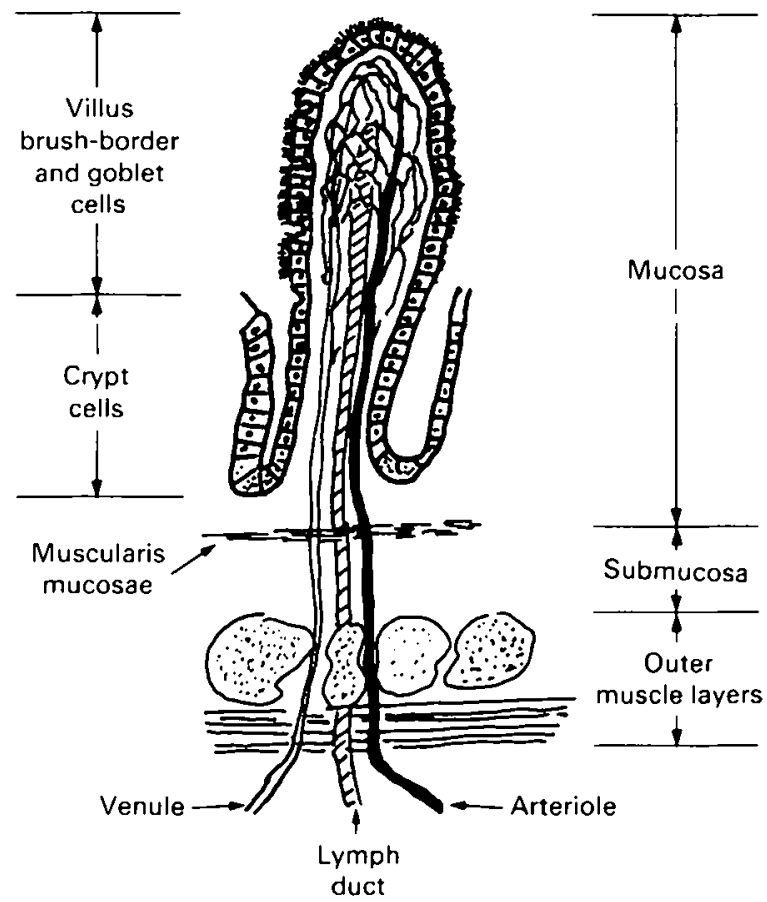

Fig. 1. Diagrammatic representation of a longitudinal section through a single villus of the small intestine. The diagram emphasizes the importance of the microcapillary bed (supplied by a single arteriole and drained by a single venule) in the villus. All plasma substrates and all oxygen in vivo reach the epithelial cells by this vascular route; substrates of luminal origin, after absorption across the brush-border membrane of the villus epithelial cells and translocation across the cells, enter the vascular bed of the intestine en route for the hepatic portal vein (see p. 144). Other capillary networks (not shown) supply the musculature. A single lymph duct provides undirectional drainage of each villus. Each villus is also equipped with a complex nerve supply (not shown).

and form part of the so-called crypts of Lieberkühn. In the mouse small intestine, there may be as many as twenty such crypts distributed about each villus (N. A. Wright, private communication). The whole luminal surface of the mucosa is lined with a unicellular layer of epithelial cells (Fig. I) sometimes called enterocytes, a generic name for at least five sub-classes: the crypt stem cells, crypt endo- and exocrine cells, the villus absorptive (brush-border) cells and the villus mucin-secreting (goblet) cells. The continuous process of epithelial cell generation from the crypt stem cells, proliferation of the progeny in the crypts and their subsequent migration out of the crypts on to the villi, followed by differentiation on the villi into brush-border and goblet cells has been described briefly (e.g. Porteous, 1979; Porteous et al. 1979; Morrison \& Porteous, 1980). One consequence of the differentiation process is the synthesis of brush-border and intracellular digestive enzymes (carbohydrases and peptidases) in the brush-border cells only; these enzymes catalyse the terminal stages of digestion of dietary carbohydrate and protein. Senescent cells are continuously desquamated from the tips of the villi and degraded within the intestinal lumen. The entire epithelial 
lining of the small intestine in vivo is normally replaced once in every $2-3 \mathrm{~d}$; in the adult human this involves replacing some $300 \mathrm{~g}$ wet weight of cells daily. A consequence of intestinal epithelial cell desquamation is that it provides a normal daily endogenous protein load on the intestine about equal to the normal daily intake of exogenous protein.

\section{Arterial supply, venous return, lymph drainage and nerve supply}

The whole of the intestine is wrapped in the peritoneum, two thin closelyopposed sheets which enclose the mesenteric tissue within which are (I) the arterial vessels carrying blood from the aorta, (2) the veins returning blood via the superior mesenteric vein and hepatic portal vein to the liver, (3) the lymph ducts draining the intestine and eventually emptying into the superior vena cava, (4) the nerves (sympathetic and parasympathetic) which control and monitor intestinal functions. The peritoneum thus suspends the intestine within the abdominal cavity and at the same time provides support for the mesentery carrying the nerves and vessels. In the rat (as in the human) a single arterial vessel (the superior mesenteric artery) arises as a branch of the aorta to supply the whole small intestine; this is achieved by branching of the artery at several points. The arterial arcades thus formed within the mesentery are matched by venous arcades returning blood from the intestine; these tributaries join to form a single vessel, the superior mesenteric vein, which drains the whole of the small intestine into the hepatic portal vein (Greene, 1963). Perfusion of the vascular bed of the whole small intestine is then possible by cannulating the superior mesenteric artery (or, with some extra ligatures applied to the aorta and its branches, by cannulating the aorta just below the point of departure of the mesenteric artery); the superior mesenteric vein can likewise be cannulated directly (or indirectly, with extra ligatures, by cannulating the hepatic portal vein just above the point of entry of the mesenteric vein). Perfusion of the vasculature of selected segments of the small intestine necessitates tying off all except the arcade of vessels supplying the selected segment. Perfusion of the lumen of the intestine is readily achieved by tying in wide-bore cannulas after sectioning the intestinal wall at the proximal and distal ends of the selected length of intestine. Lumen and vascular bed may then each be perfused with separate media. In some studies, the lumen alone is perfused with experimental fluid; the vascular bed of the intestine continues to be perfused by the animal's blood supply under anaesthesia. It is possible also to collect the whole lymph draining the small intestine (Windmueller et al. 1970; Windmueller \& Spaeth, 1972, 1974) but, since total lymph flow from the intestine is but a very small part of total blood flow through the intestine, this is infrequently done unless there is a special need to study lymph drainage.

\section{The microvasculature of intestinal tissue}

Some of the problems which may be encountered in maintaining a vascular perfusion can only be understood by appreciating how blood vessels are arranged and their dilation or constriction controlled. Further details of the intra-intestinal 
vascular bed are given by Folklow \& Neil (1971) and (for the villus alone) by Masoro (1973). Capillary shunts (within intestinal tissue) between the incoming arterial supply and the outgoing venous return have also been described (Folklow \& Neil, 197I).

\section{Control of blood flow through the intestine}

Neural and hormonal effectors control total blood flow though any given volume of intestinal tissue, and distribution of flow amongst different parts of the tissue, by adjusting the tone of smooth muscle in arterial and venous vessels and by constricting or relaxing 'sphincters' located just distal to branch points on the arterial side of the intra-intestinal capillary beds described previously. Analogous regulations of blood flow occur in the mesenteric arcades. The complexities of flow regulation (for reviews, see Kosterlitz \& Lees, 1964; Davenport, 1971; Furness \& Marshall, 1972; Henrich \& Biester, 1972; Granger et al. 1980; Granger, 1981; Wood, 198I) may be critical to the maintenance of a vascular perfusion of intestine, especially in those systems where the intestine is segregated from its normal neural connections and from its usual supply of extra-intestinal hormones. Some investigators (Windmueller \& Spaeth, 1972, 1974) incorporate dexamethasone and infuse noradrenalin into the vascular perfusion fluid, and regard these steps as essential for the maintenance of the perfusion; others, using a similar intestinal preparation (Hanson \& Parsons, 1976, 1977, 1978; Bronk \& Ingham, 1979; Nicholls et al. 1983), do not find such additions to the vascular perfusate necessary. Preparations in which blood is transfused (albeit from donor rats) through the surviving animal under anaesthetic, and in which the experimental segment of intestine is still connected to its normal arterial blood supply routes and neural tracts, do not require hormone supplementation in the vascular perfusate (Windmueller \& Spaeth, 1975, 1976, 1977, 1978, 1980).

\section{Plasma skimming, perfusate viscosity, erythrocyte deformability}

It has been established (Jodal \& Lundgren, 1970) that erythrocytes flow in the axial stream (in blood vessels with diameters less than 200-250 $\mu \mathrm{m}$ ); the suspending plasma in contact with blood vessel walls may be flowing more slowly than the erythrocytes. At branches in the capillary vascular beds a population of flowing erythrocytes may not segregate equally under all conditions between each of two branches of the vascular bed. When there is pronounced unequal distribution of suspended erythrocytes between different regions of the vascular bed, 'plasma skimming' has occurred and some parts of the tissue will then receive less oxygen than others (assuming equal total fluid flow-rates through both branches). Jodal \& Lundgren (1970) demonstrated plasma skimming in the small intestine (and colon) of chloralose-anaesthetized cats, such that epithelial cells at the tips of the small intestinal villi were likely to receive a smaller supply of $\mathrm{O}_{2}$ (but not of plasma solutes) than were those at the base of the crypts. Such plasma skimming is likely to be determined by a variety of factors including the local velocity of blood flow, the geometry and elasticity of branching blood vessels, the 
viscosity of the suspending fluid and the deformability of the erythrocytes. The interplay of these various factors has not been quantitatively evaluated to our knowledge. Commentaries on factors influencing erythrocyte deformability have been given by Weed et al. (1969), Rogausch (1972), Weinstein (1974) and Tadano et al. (1977) and are relevant for those interested in the preparation of suspensions of erythrocytes for incorporation into vascular perfusion media.

\section{Unusual restrictions of blood flow through the perfused intestine; artefacts and accidents}

It is obvious that blood coagulation must be avoided. Coagulation in those perfusates containing resuspensions of erythrocytes in a medium of suitable ionic strength and composition is avoided, provided the erythrocytes have been adequately and carefully washed beforehand. But blood cell aggregates, as distinct from coagulates, may well block some fine capillaries with a subsequent escalating failure of the preparation; useful comments on erythrocyte aggregation have been given by Volger et al. (1972). Non-cellular organic or inorganic debris of any kind may cause similar difficulties because of the nature of the intestinal vascular bed; ultra-filtration of the suspending medium and careful preparation of erythrocytes before they are added, pays dividends.

\section{$\mathrm{O}_{2}$ loading and unloading of the erythrocytes during vascular perfusion of the intestine}

Given the perfect perfusion of the vascular bed of intestine (in vivo) or its near perfect perfusion (in vitro), there remains consideration of the effective loading of erythrocyte haemoglobin with $\mathrm{O}_{2}$ on the arterial side of the perfusion, and the effective unloading of $\mathrm{O}_{2}$ within the respiring intestinal tissue. The role of 2,3-bisphosphoglycerate $\left(2,3-\mathrm{GriP}_{2}\right)$ in modifying the $\mathrm{O}_{2}$-saturation curve of the haemoglobins of many species of erythrocyte is well known (Chiba \& Sasaki, 1978).

Formation of $2,3-\mathrm{GriP}_{2}$ from $1,3-\mathrm{GriP}_{2}$ is catalysed by bisphosphoglycerate mutase; formation of $3-\mathrm{GriP}$ and $\mathrm{P}_{i}$ from the $2,3-\mathrm{GriP}_{2}$ is catalysed by a phosphatase. Under conditions found in vivo, about $20 \%$ of the total glycolytic flux in human erythrocytes passes through this 'by-pass' route and control of the steady-state $2,3-\mathrm{GriP}_{2}$ concentration resides predominantly with the hexokinase $(E C$ 2.7.1.1), phosphofructokinase ( $E C$ 2.7.I.1 I), and ATPase ( $E C$ 3.6.1.8) catalysed steps (Rapoport et al. 1976). Under blood-bank storage conditions, the $2,3-\mathrm{GriP}_{2}$ concentration falls from its normal concentration $(4-5 \mathrm{~mm}$ in human cells) to about $25 \%$ of this value in $10 \mathrm{~d}$ and to less than $10 \%$ in $21 \mathrm{~d}$. Restoration of the $2,3-\mathrm{GriP}_{2}$ concentraton to $4-5 \mathrm{~mm}$ by incubation of depleted human erythrocytes with glucose is an exceedingly slow process (Rapoport et el. 1976) and other procedures (Oski et al. I971) have been proposed; these latter procedures can yield 8-10 $\mathrm{mm}-2,3-\mathrm{GriP}_{2}$ in the erythrocyte, a concentration which is reported not to affect $\mathrm{O}_{2}$ loading or unloading but which does inhibit erythrocyte glycolysis (Chiba \& Sasaki, 1978). 

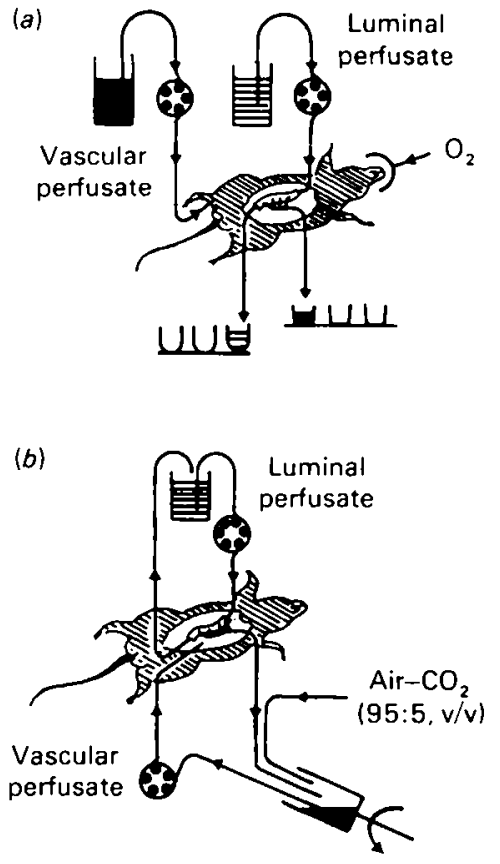

Fig. 2. Diagrammatic representation of two versions of the vascular and luminal perfusion of rat small intestine. (a) The 'once-through' system. Medium is pumped once through the lumen of a selected segment of intestine that is served and drained by one or more arcades of blood vessels. The segment is also vascularly perfused by another medium (usually rat donor blood introduced via a saphenous vein) which circulates through the anaesthetized rat and is oxygenated in the lungs before reaching the intestine via the superior mesenteric artery; any isotopically-labelled vascular substrates are infused just before the blood enters the arterial arcades serving the selected segment. All venous blood draining the segment is collected for analysis. Neural and humoral interactions between the intestine and the rest of the animal are retained (e.g. Windmueller \& Spaeth, 1978, I980). (b) The recirculation system. Medium is recirculated through the lumen of a segment of small intestine selected as before. The segment is perfused through the vascular bed via the superior mesenteric artery and vein by an extracorporeal supply of a suitable medium (usually a suspension of erythrocytes in Kreb-Henseleit bicarbonate solution) which is recirculated via an oxygenator flushed with oxygen-carbon dioxide or (in our laboratory) with air- $-\mathrm{CO}_{2}(95: 5, \mathrm{v} / \mathrm{v}$ ) (e.g. Hanson \& Parsons, 1977).

Clearly, the choice of erythrocytes and treatment before incorporation into the medium is a matter of some importance. There is, nevertheless, controversy over the effectiveness of 'aged' and 'restored' human erythrocytes in perfusion media (for example, see Rennie \& Hollosey, 1977; Ruderman et al. 1980).

\section{Uses of the perfused rat small intestine}

The following examples are intended only to illustrate the wealth of information that can be obtained by skilled use of the perfused small intestine.

Recirculation and 'once-through' perfusion systems. The papers by Windmueller \& Spaeth (1978, 1980) and by Hanson \& Parsons (1977) have been selected because 
they involve a study of the fate of the same substrates in two different perfusion systems for rat jejunum: the essential differences between the two systems are illustrated in Fig. 2. Windmueller \& Spaeth (1978, 1980) used a 'once-through' perfusion of both the intestinal lumen and of the vasculature of the intestine (Fig. 2a). In contrast, Hanson \& Parsons (1977) used a recirculation system for both the luminal and the vascular perfusate (Fig. $2 b$ ).

The fate of plasma substrates in the perfused small intestine. Fig. $3 a$ summarizes some results obtained by Windmueller \& Spaeth (1978) on the fate of plasma glutamine in the small intestine. An earlier finding (Windmueller \& Spaeth, 1974) that intestine extracted about $30 \%$ of plasma glutamine during each pass of normal blood through the intestine in vivo was confirmed. The percentage distribution of the metabolized glutamine among a number of products is also indicated; notable are the significant incorporation into acid-insoluble tissue products (presumably protein) and the $55 \%$ conversion to carbon dioxide. In analogous experiments (Windmueller \& Spaeth, 1978, 1980) it was shown that in rats starved overnight, arterial L-glutamine contributed $35 \%, 3$-hydroxybutyrate $26 \%$, acetoacetate $24 \%$, D-glucose $7 \%$, L-lactate $5 \%$ and unesterified fatty acids $3 \%$ to the total $\mathrm{CO}_{2}$ production of the perfused intestinal tissue; in fed rats, the corresponding values (\%) for the first four substrates were $46,3,11,10$ (all values corrected to the nearest whole number). Although in the intestines of fed rats, the origin of $30 \%$ of the total $\mathrm{CO}_{2}$ is as yet unaccounted for, these remarkable experiments show clearly that in both the fasted and fed state, arterial L-glutamine is the dominant respiratory substrate for intestine; and that intestinal metabolism of plasma L-glutamine contributes significantly to whole-body metabolism of this amino acid; further, that plasma glucose (normally present at ten to twelve times the glutamine concentration) contributes relatively little to the respiratory activity of intestine. Only $2 \%$ of the glucose was extracted during passage of the vascular perfusate through the intestine (Fig. $3 b$ ). The per cent distribution of this extracted glucose among a number of products is indicated. Notable are the significant incorporations into acid-insoluble tissue products (11\%) and into tissue lipids $(14 \%)$; lactate was the dominant product $(43 \%)$, followed by alanine $(13 \%)$ and $\mathrm{CO}_{2}(\mathrm{II} \%$ ) appearing in the venous effluent from the perfused intestine.

In analogous experiments, Hanson \& Parsons (1977) showed that L-glutamine was extracted from the vascular perfusate at different rates by intestines taken from fed, starved and acidotic rats; of the glutamine extracted by the intestine, $3^{6-50 \%}$ was metabolized to alanine and returned to the vascular perfusate (Fig. $3 c$ ). Whether these greater percentage yields of alanine (cf Fig. $3 a$ ) from the metabolized glutamine are to be attributed to the differences in initial glutamine concentration, or to the different respiration rates observed (Fig. $3 a, c$ ) or to other causes remains to be seen; in both sets of experiments glucose $(7.5 \mathrm{~mm})$ was present in the vascular perfusate. Windmueller \& Spaeth (1980) observed differences (sometimes quite marked) in rates of uptake or release of substrates and products when results for intestines from fed and starved rats were compared, but found (in contrast to Hanson \& Parsons, 1977; Fig. $3 c$ ) that rates of glutamine extraction were unaffected. 

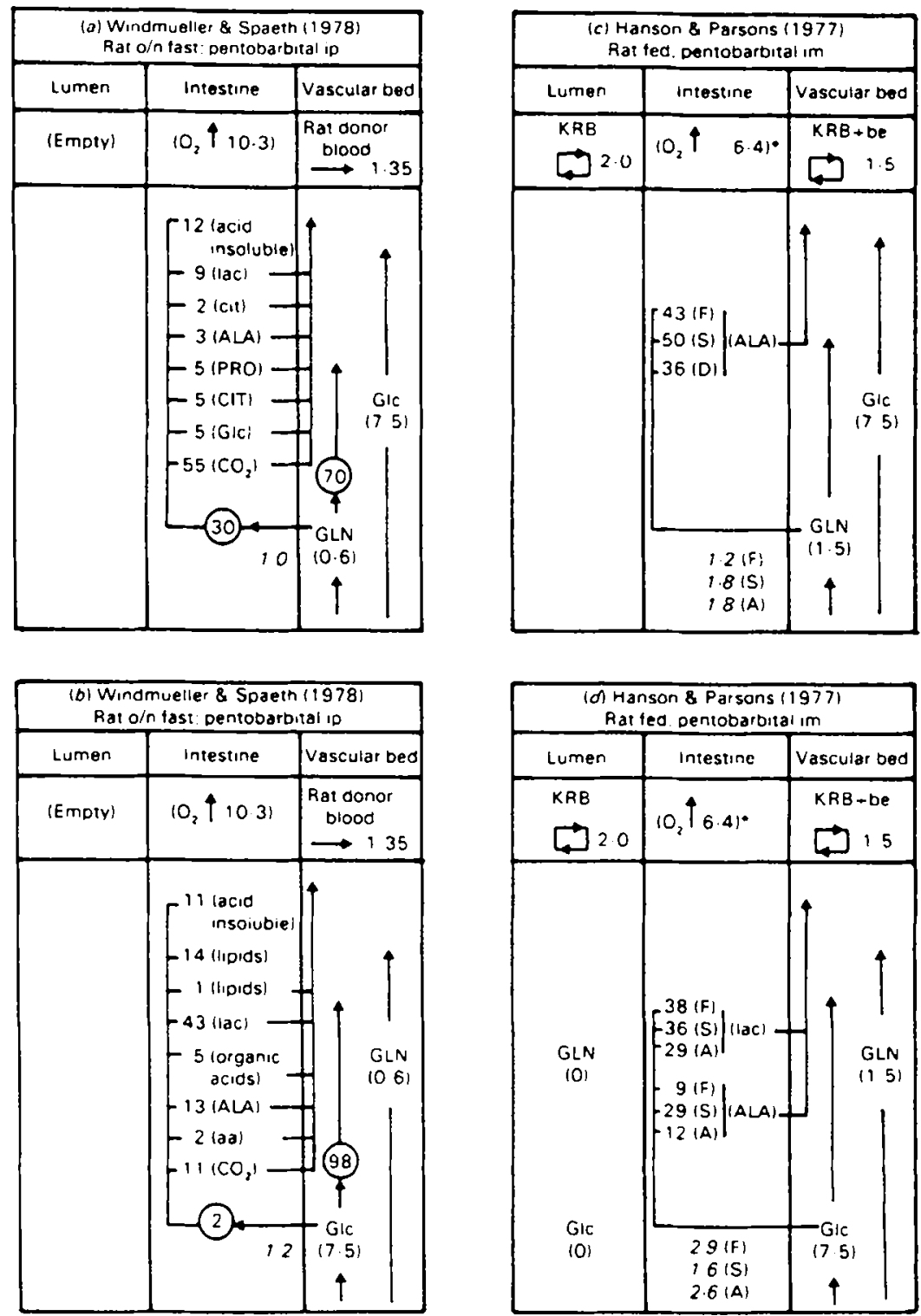

Fig. 3. Flow diagrams showing the fate of vascular perfusate substrates in the perfused small intestine of the rat; from results of Windmueller \& Spaeth $(1978,1980)$ and Hanson \& Parsons (1977). o/n, Overnight; ip, intraperitoneal; im, intramuscular; KRB, Krebs-Ringer bicarbonate solution; be, bovine erythrocytes; $\rightarrow, \vec{L}$, once-through and recirculation perfusions respectively (values given are flow-rates $(\mathrm{ml} / \mathrm{min})$ ); lac, lactate; cit, citrate; ALA, alanine; PRO, proline; CIT, citrulline; GLU, glutamic acid; GLN, glutamine; Gle, glucose; aa, amino acids; F, fed; S, starved; $A$, acidotic. $\mathrm{O}_{2}{ }^{\dagger}$, respiration rates $(\mu \mathrm{mol} / \mathrm{min}$ per $\mathrm{g}$ dry weight). Values shown with an asterisk are taken from Hanson \& Parsons (1976). Values shown in italics are rates of absorption from the luminal perfusate or of extraction from the vascular perfusate ( $\mu \mathrm{mol} / \mathrm{min}$ per $\mathrm{g}$ dry tissue). Values shown in parentheses are the initial concentrations (mM) of substrates in the perfusates. Values shown in circles are the percentage distributions of the substrate between the two routes shown; values shown for the products formed in intestinal tissue are the percentage distributions of the metabolized substrate among these products. 
Hanson \& Parsons (1977) also studied glucose extraction from the vascular perfusate (Fig. $3 d$ ). Rates of extraction by intestines from fed, starved and acidotic rats differed quite markedly but, for intestines from starved rats, were very close to rates observed by Windmueller \& Spaeth (1978, 1980; Fig. $3 b$ ); the yields of lactate $(29-38 \%$, assuming glucose to be the only source of lactate) were of the same order as that shown in Fig. $3 b$. Yields of alanine, again assuming glucose to be the only source of alanine-carbon, varied with the physiological state of the animal (Fig. $3 d$, cf Fig. $3 c$ ).

The fate of lumen substrates in the perfused intestine. Fig. 4 summarizes some results obtained by Windmueller \& Spaeth (1975, 1980) and by Hanson \& Parsons (1977) when segments of small intestine were perfused simultaneously by the luminal and vascular routes. As it had been demonstrated that plasma glutamine was a dominant substrate supporting intestinal respiration, the fates of lumen glutamine and glucose were interesting. Windmueller \& Spaeth (1 975) showed that, under steady-state conditions, $34 \%$ of glutamine was translocated unchanged from the luminal perfusate into the vascular perfusate (whole rat blood) already containing, inter alia, glutamine $(0.6 \mathrm{~mm})$ and glucose $(7.5 \mathrm{~mm}) ; 64 \%$ of the absorbed glutamine was metabolized, the dominant products being $\mathrm{CO}_{2}$ and lactate ( 56 and $16 \%$ of the glutamine metabolized) as shown in Fig. $4 a$. Apart from $6 \%$ of the glutamine-C which remained in the tissue, all the other products appeared in the vascular perfusate and would (in vivo) immediately enter the liver via the hepatic portal vein. In these experiments, intestines were taken from rats fasted overnight. In similar experiments (Fig. $4 b$ ), Windmueller \& Spaeth (1980) used short segments of jejunum from fed rats and showed that, of the glucose which was absorbed during perfusion through the lumen of the intestine, $97 \%$ was translocated unchanged into the vascular perfusate which already contained, inter alia, $7.5 \mathrm{~mm}$-glucose. From the $3 \%$ of absorbed glucose that was metabolized, the dominant metabolites formed were lactate, $\mathrm{CO}_{2}$ and alanine as shown.

It seems from these observations that glucose in the luminal perfusate (corresponding to dietary glucose) is not markedly metabolized by starved or fed intestine and, in particular, does not support significantly intestinal respiration. These important observations are completely at variance with earlier perceptions of intestinal metabolism obtained largely from studies with everted sacs. Hanson \& Parsons (1976) demonstrated unequivocally that everted sacs could not be oxygenated effectively.

Hanson \& Parsons (1977), using their recirculation system, showed that $38 \%$ of the glutamine absorbed from the luminal circuit appeared unchanged in the vascular circuit of perfused rat jejunum that contained $7.5 \mathrm{~mm}$-glucose but initially no glutamine (Fig. 4 c). Of the glutamine metabolized, $67 \%$ appeared as alanine in the vascular circuit (calculated on the assumption that glutamine was the only source of alanine). Similarly, $44 \%$ of the glucose absorbed from the lumen appeared as unchanged glucose in the vascular circuit which contained, initially, no glucose (Fig. ${ }_{4} d$ ). Of the $56 \%$ of absorbed glucose that was metabolized, $52 \%$ appeared as lactate (again, assuming that glucose was the only source of this lactate). 

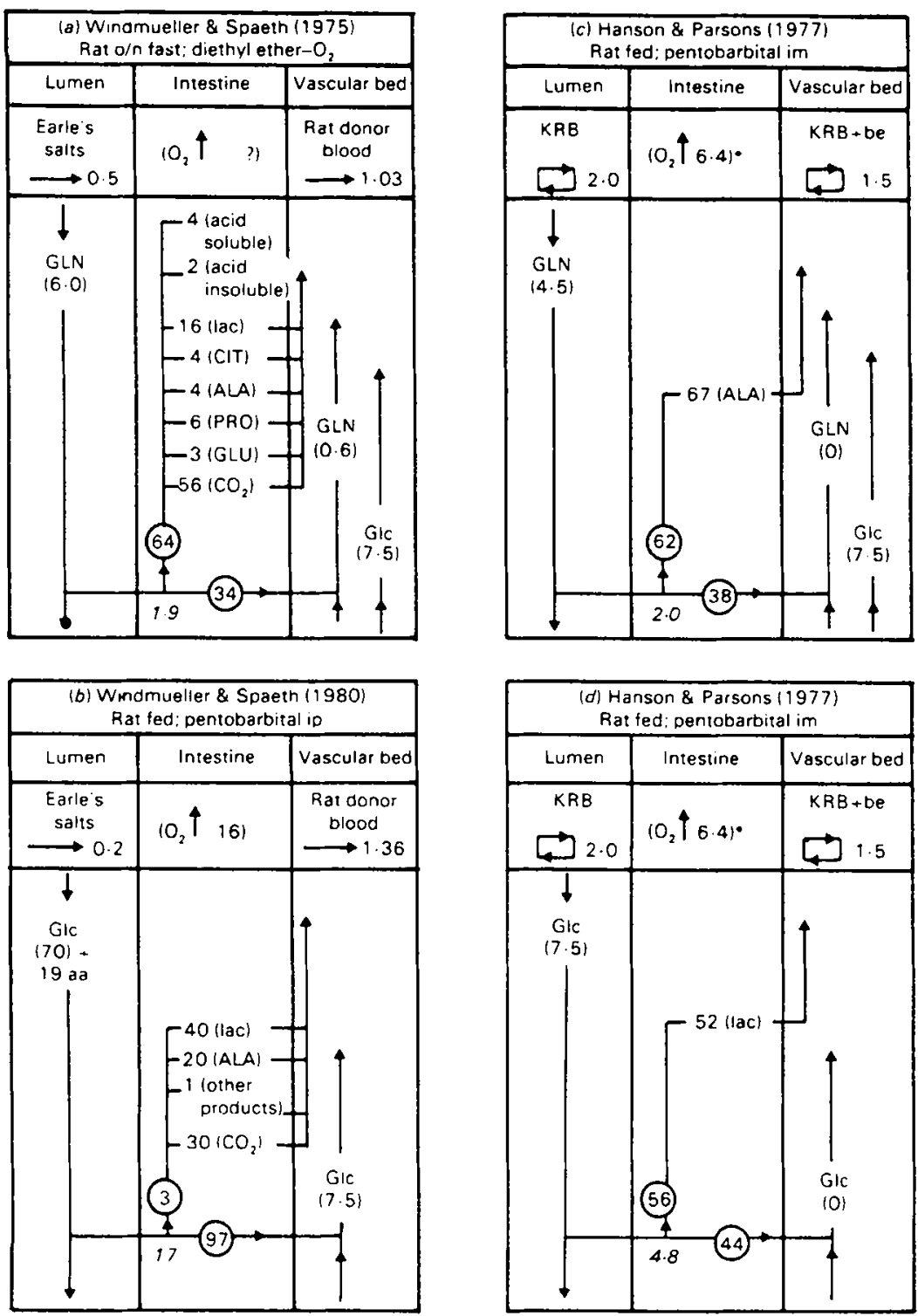

Fig. 4. Flow diagrams showing the fate of luminal perfusate substrates in the perfused small intestine of the rat; from results of Windmueller \& Spaeth $(1975,1978,1980)$ and Hanson \& Parsons (1977). o/n, Overnight; ip, intraperitoneal; im, intramuscular; KRB, Krebs-Ringer bicarbonate solution; be, bovine erythrocytes; $\rightarrow, \vec{L} \mid \vec{b}$, once-through and recirculation perfusions respectively (values given are flow-rates $(\mathrm{ml} / \mathrm{min})$ ); lac, lactate; cit, citrate; ALA, alanine; PRO, proline; CIT, citrulline; GLU, glutamic acid; GLN, glutamine; Glc, glucose; aa, amino acids; F, fed; S, starved; A, acidotic. $\mathrm{O}_{2}^{\dagger}$, respiration rates $(\mu \mathrm{mol} / \mathrm{min}$ per $\mathrm{g}$ dry weight). Values shown with an asterisk are taken from Hanson \& Parsons ( 1976$)$. Values shown in italics are rates of absorption from the luminal perfusate or of extraction from the vascular perfusate ( $\mu \mathrm{mol} / \mathrm{min}$ per $g$ dry tissue). $V$ alues shown in parentheses are the initial concentrations (mM) of substrates in the perfusates. Values shown in circles are the percentage distributions of the substrate between the two routes shown; values shown for the products formed in intestinal tissue are the percentage distributions of the metabolized substrate among these products. 
Further information on rat small intestinal metabolism will be found in papers by Windmueller et al. (1970), Parsons \& Powis (1971), Windmueller \& Spaeth (1972, I974, 1975, 1976, 1977, I980), Hanson \& Parsons (1976, 1977, 1978), Boyd \& Parsons (1978), Bronk \& Ingham (1979) and Nicholls et al. (1983). Information summarized in Figs. 3 and 4 is, nevertheless, sufficient to demonstrate the utility of the vascularly- and luminally-perfused intestine as an experimental system in nutritional studies generally and in metabolic studies in particular. For example, note the observations of Windmueller \& Spaeth (1978) that anaesthesia with diethyl ether $-\mathrm{O}_{2}$ raised the arterial lactate concentration above $\mathrm{I} \mathrm{mm}$, and that intestine then became a net consumer of lactate; whereas sodium pentobarbital anaesthesia left arterial lactate at less than I $\mathrm{mm}$ and, under these circumstances (given appropriate substrates), intestine became a net producer of lactate.

\section{The use of human erythrocytes in perfusions of rat intestine}

For several reasons, it was decided to use human erythrocytes (from out-dated blood-bank packs) in perfusion experiments with rat jejunum in this laboratory. In such erythrocytes the ATP concentration was commonly less than $I \cdot 0 \mu \mathrm{mol} / \mathrm{ml}$ packed cells and the $2,3-\mathrm{GriP}_{2}$ concentration commonly less than $2.0 \mu \mathrm{mol} / \mathrm{ml}$ packed cells. Incubation of such cells at $37^{\circ}$ with glucose $(5 \mathrm{~mm})$ in Krebs-Henseleit bicarbonate $(\mathrm{K}-\mathrm{H})$ buffer (equilibrated with air- $\mathrm{CO}_{2}(95: 5 \mathrm{v} / \mathrm{v})$ to give $\mathrm{pH} 7.4$ ) restored the ATP concentration to $\mathrm{I} .45 \mathrm{mM}$ within $\mathrm{I} 20 \mathrm{~min}$ but the $2,3-\mathrm{GriP}_{2}$ concentration rose only slowly to about $3.5 \mathrm{~mm}$ over $\mathrm{I} 80 \mathrm{~min}$ (Fig. 5 ) and the rate of increase in concentration then declined. Rapoport et al. (1976) showed that the normal ATP concentration of human erythrocytes was I.2$\mathrm{I} \cdot 3 \mathrm{mM}$ and the normal $2,3-\mathrm{GriP}_{2}$ concentration $4.5-5.0 \mathrm{~mm}$ and that the concentration of the latter ester was only slowly restored in depleted erythrocytes if they were incubated with glucose. Incubation of depleted erythrocytes with phosphate $(5 \mathrm{~mm})$, pyruvate $(5 \mathrm{mM})$, adenine $(0.5 \mathrm{mM})$ and inosine $(5 \mathrm{mM})$ at $37^{\circ}$

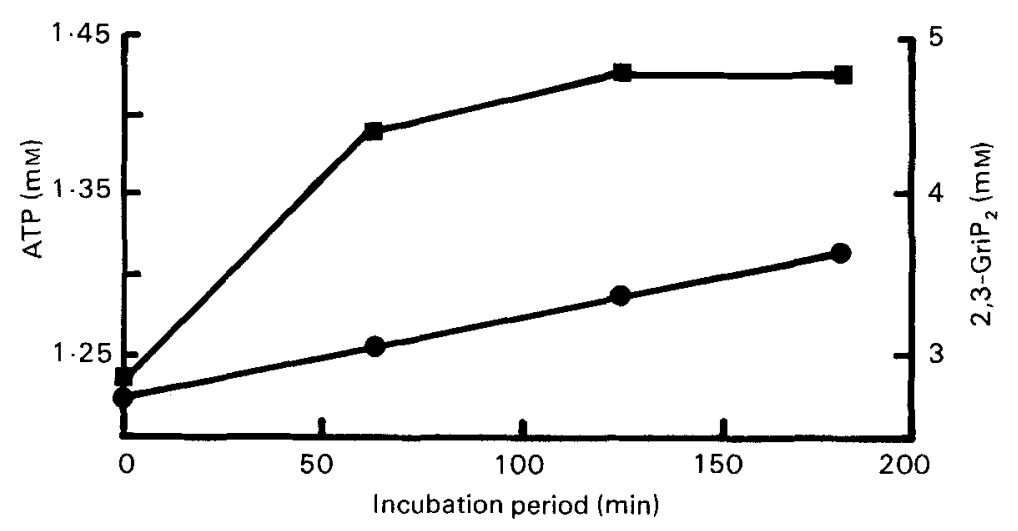

Fig. 5. Changes in the concentration of intracellular ATP (ש) and 2,3-bisphosphoglycerate $\left(2,3-\mathrm{GriP}_{2} ; 0\right)$ during incubation of human erythrocytes with glucose $(5 \mathrm{~mm})$ at $37^{\circ}$. Erythrocytes were taken from out-dated blood-bank stocks, washed and suspended in Kreb-Henseleit bicarbonate solution + glucose $(5 \mathrm{~mm})$ and equilibrated with air-carbon dioxide $(95: 5, \mathrm{v} / \mathrm{v})$ to $\mathrm{pH}$ $7 \cdot 4$, then incubated at $37^{\circ}$. 
(Valeri, 1974 ) for $60 \mathrm{~min}$ brought the ATP to $\mathrm{I} \cdot 80_{-1} \cdot 85 \mathrm{mM}$ and the $2,3-\mathrm{GriP}_{2}$ to about $8 \mathrm{~mm}$. 'Restored' cells were washed by centrifugation and suspended in $\mathrm{K}-\mathrm{H}$ buffer. During a preperfusion period (detailed in Fig. 6) the ATP decreased to a steady $\mathrm{I} \cdot 55 \mathrm{mM}$ and the $2,3-\mathrm{GriP}_{2}$ remained approximately constant between 7.5 and $8.0 \mathrm{~mm}$ (Fig. 7). These 'restored' erythrocytes, washed and resuspended in $\mathrm{K}-\mathrm{H}$ buffer to a packed cell volume of 0.40 , and supplemented with glucose $(5 \mathrm{mM})$, gave entirely satisfactory vascular perfusions at $37^{\circ}$ in a recirculating system (Fig. $2 b$ ) provided dexamethasone $\left(25^{\circ} \mathrm{ng} / \mathrm{ml}\right.$ ) was added initially to the vascular perfusion and noradrenalin was infused at $100 \mathrm{ng} / \mathrm{min}$ into the vascular perfusate (Windmueller et al. 1970 ) throughout; the luminal perfusate was $\mathrm{K}-\mathrm{H}$ buffer, supplemented with glucose ( $15 \mathrm{mM}$ ). Recovery of vascular and luminal fluid volumes after $60 \mathrm{~min}$ perfusions were regularly better than $95 \%$. In the absence of dexamethasone and noradrenalin, the hyperaemia, irregular contractions and low vascular resistance noted by Windmueller et al. (1970) were manifest. But, even with these additions to the vascular perfusate, perfusions failed within the first 10-20 $\mathrm{min}$ if the human erythrocytes were not pretreated as described to elevate their ATP and 2,3-GriP ${ }_{2}$ concentrations (Fig. 7): histological examination showed

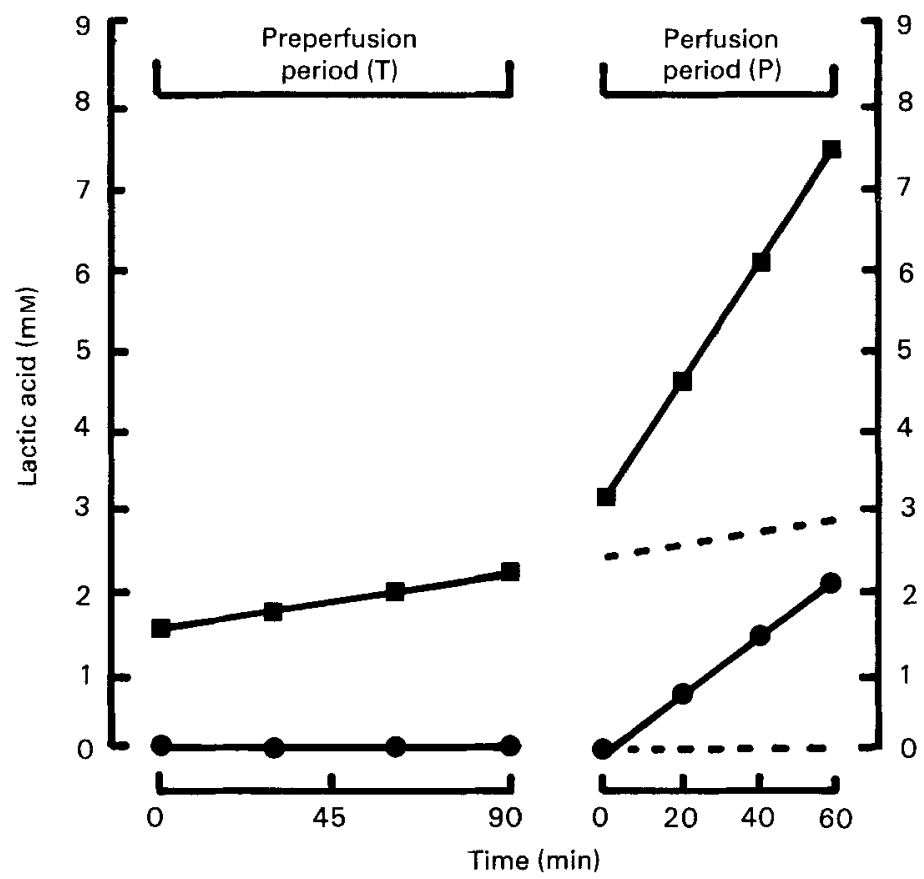

Fig. 6. Typical experimental procedure for perfusion of rat small intestine in the recirculation mode. The diagram illustrates lactate appearing in the vascular $(\square)$ and luminal $(\boldsymbol{O})$ circuits; analogous diagrams would apply for each substrate under investigation. During a preperfusion period $\left(T_{0}-T_{90}\right)$ the media are circulated through the apparatus without the intestine; determinations are made of any substrates disappearing and of any products formed. Linear rates of substrate consumption and of product formation while the intestine is being perfused $\left(P_{0}-P_{60}\right)$ are corrected for changes observed during the preperfusion period. The packed cell volume, oxygen pressure and $\mathrm{pH}$ of the vascular perfusate are monitored during both periods; arterio-venous differences in oxygen concentration are measured during the perfusion period. 


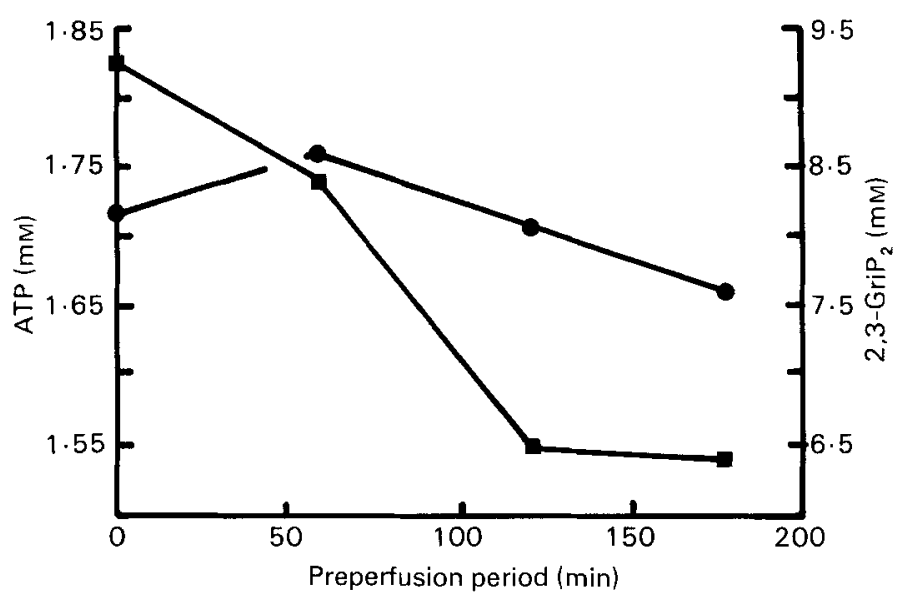

Fig. 7. Changes in the ATP $(\boldsymbol{D})$ and 2,3 -bisphosphoglycerate $\left(2,3-\mathrm{GriP}_{2} ; \boldsymbol{\theta}\right)$ concentrations of human erythrocytes during a preperfusion period (see Fig. 6) using erythrocytes previously treated to elevate their depleted concentrations of ATP and $2,3-\mathrm{GriP}_{2}$.

that the intestinal capillary bed was blocked by erythrocytes and the villi showed severe epithelial cell necrosis and destruction of the subepithelial tissue.

Under satisfactory perfusion conditions, with $5 \mathrm{~mm}$-glucose in the vascular perfusate flowing at $1.4 \mathrm{ml} / \mathrm{min}$ (arterial pressure $70 \mathrm{~mm} \mathrm{Hg}$ ), and $15 \mathrm{~mm}$-glucose in the luminal perfusate flowing at $2 \mathrm{ml} / \mathrm{min}$, the mean respiration rate over $60 \mathrm{~min}$ at $37^{\circ}$ was 5.2 ( $\left.\mathrm{SE} 0.62\right) \mu \mathrm{mol} \mathrm{O} / \mathrm{min}$ per $\mathrm{g}$ dry weight for intestines taken from fed rats; for intestines taken from rats allowed water $a d l i b$. but otherwise starved for $48 \mathrm{~h}$, the corresponding respiration rate was 3.54 (SE I 30 ) $\mu \mathrm{mol} \mathrm{O}_{2} / \mathrm{min}$ per $\mathrm{g}$ dry weight. Net glucose absorption and extraction rates, and net lactate yields by these intestines are recorded in Table I. These metabolic rates may be compared with those summarized in Figs. 3 and 4.

\section{Water absorption by the luminally-perfused intestine}

For these experiments, the perfusion system shown diagrammatically in Fig. $2 b$ was modified so that only the lumen was perfused with experimental solution; the vascular bed continued to be perfused by the normal circulation with the rat under sodium pentobarbital anaesthesia. Net water absorption was measured directly by noting the volume of the luminal perfusate at the beginning and end of the $60 \mathrm{~min}$ perfusion (allowing for the volume of samples removed). Results are shown in Fig. 8. The proprietary preparations Dioralyte ${ }^{\circledR}$ (Armour) and Rehidrat ${ }^{\circledR}$ (Searle) are marketed to be taken orally in solution in order to enhance water absorption from the gut. It is notable that the Dioralyte solution (containing 34 mM-sodium chloride, $40 \mathrm{~mm}$-potassium chloride, $36 \mathrm{~mm}$-sodium bicarbonate, $200 \mathrm{~mm}$-glucose) gave a water absorption rate identical with that given by $\mathrm{K}-\mathrm{H}$ buffer modified to include $200 \mathrm{~mm}$-glucose but only $54 \mathrm{~mm}-\mathrm{NaCl}$ (instead of the usual $154 \mathrm{~mm}-\mathrm{NaCl}$ ); the Rehidrat solution (containing $30 \mathrm{~mm}-\mathrm{NaCl}, 2 \mathrm{I} \mathrm{mM}-\mathrm{KCl}, 20 \mathrm{~mm}-\mathrm{NaHCO}_{3}$, I 8 mM-citric acid, $90 \mathrm{~mm}$-glucose, $94 \mathrm{~mm}$-sucrose, I-5 mM-fructose) supported 
Table I. Summary of rates of absorption of glucose from the luminal perfusate, of glucose extraction from the vascular perfusate, of lactate production and of respiration rates in jejunums taken from fed rats and from rats starved for $24 h$ before perfusing the lumen and vascular bed

(Perfusion conditions were those detailed in Fig. Io. Respiration rates were calculated (Windmueller et al. 1970) from concomitant measurements of oxygen pressure, carbon dioxide pressure and $\mathrm{pH}$ on arterial and venous samples of the vascular perfusate. Values shown are means and standard deviations; nos. of determinations from separate experiments are shown in parentheses)

\begin{tabular}{|c|c|c|c|c|c|}
\hline \multirow{4}{*}{$\begin{array}{l}\text { Lumen glucose }(\mathrm{m} M) \ldots \\
\text { Vascular glucose }(\mathrm{mM}) \ldots\end{array}$} & \multicolumn{3}{|c|}{ Fed rats } & \multirow{2}{*}{\multicolumn{2}{|c|}{$\begin{array}{l}\text { Rats starved for } \\
24 \mathrm{~h} \\
\text { I5 }\end{array}$}} \\
\hline & \multirow{2}{*}{\multicolumn{2}{|c|}{$\begin{array}{r}\mathrm{I}_{5} \\
5\end{array}$}} & \multirow{3}{*}{$\begin{array}{r}50 \\
5\end{array}$} & & \\
\hline & & & & & \\
\hline & Mean & $\overline{\mathrm{SD}}$ & & Mean & $\overline{\mathrm{SD}}$ \\
\hline $\begin{array}{l}\text { Glucose absorption from } \\
\text { the luminal perfusate } \\
\text { ( } \mu \mathrm{mol} / \mathrm{min} \text { per } \mathrm{g} \text { dry } \mathrm{wt})\end{array}$ & $5 \cdot 86$ & $0.95(13)$ & $\mathrm{I} 7 \cdot 7$ (I) & $9 \cdot 59$ & $0.29(5)$ \\
\hline $\begin{array}{l}\text { Glucose extracted from } \\
(-) \text { or released into }(+) \\
\text { the vascular perfusate } \\
(\mu \mathrm{mol} / \mathrm{min} \text { per g dry } \mathrm{wt})\end{array}$ & -0.98 & $0.66\left(1_{3}\right)$ & $+2 \cdot 85(\mathrm{I})$ & $+0.3^{8}$ & $\mathrm{x} \cdot 99(5)$ \\
\hline$\frac{\text { Total lactate formed }(\%)}{\text { Total glucose consumed }}$ & $42 \cdot 7$ & $8 \cdot 43$ & $29(1)$ & $26 \cdot 6$ & $4 \cdot 54(5)$ \\
\hline $\begin{array}{l}\text { Respiration rate }\left(\mu \mathrm{mol} \mathrm{O} \mathrm{O}_{2} /\right. \\
\text { min per g dry wt) }\end{array}$ & $5 \cdot 2$ & $0.62(3)$ & $7.9(1)$ & $3 \cdot 54$ & I. $30(5)$ \\
\hline
\end{tabular}

considerably less water absorption than did the Dioralyte although on complete hydrolysis by the intestine of the sucrose in Rehidrat, the total hexose available to the intestine would have been about $30 \%$ greater than that available in the Dioralyte solution. Comparison with other published work shows that (a) three times more water was absorbed than in the intestinal preparation of Windmueller \& Spaeth (1978) where $70 \mathrm{~mm}$-glucose (in Earle's salt solution) was also used; (b) rates of water absorption with $10-30 \mathrm{mM}$-glucose were identical to rates of water translocation found by Hastewell \& Parsons (1984) using ro-30 mM-fructose or Iо- $30 \mathrm{~mm}$-sucrose in the luminal perfusate.

In the experiments described, higher initial concentrations of glucose were accommodated in the luminal perfusate by omitting isosmolar concentrations of $\mathrm{NaCl}$ from the buffer; it was then impossible to decide whether it was the increasing glucose or the decreasing $\mathrm{NaCl}$ concentration, or both, which accounted for the slope of the plot of water absorption $v$. glucose concentration (Fig. 8). In a further series of perfusions, the lumens of selected segments of rat jejunum were perfused with $\mathrm{K}-\mathrm{H}$ solutions made increasingly hyperosmotic by the addition of glucose up to $200 \mathrm{mM}$. The resulting plot of water absorption $v$. lumen glucose concentration and water absorption $v$. osmolarity of luminal perfusate showed that the perfused intestine continued to absorb water, albeit at slower rates than before. Only when 


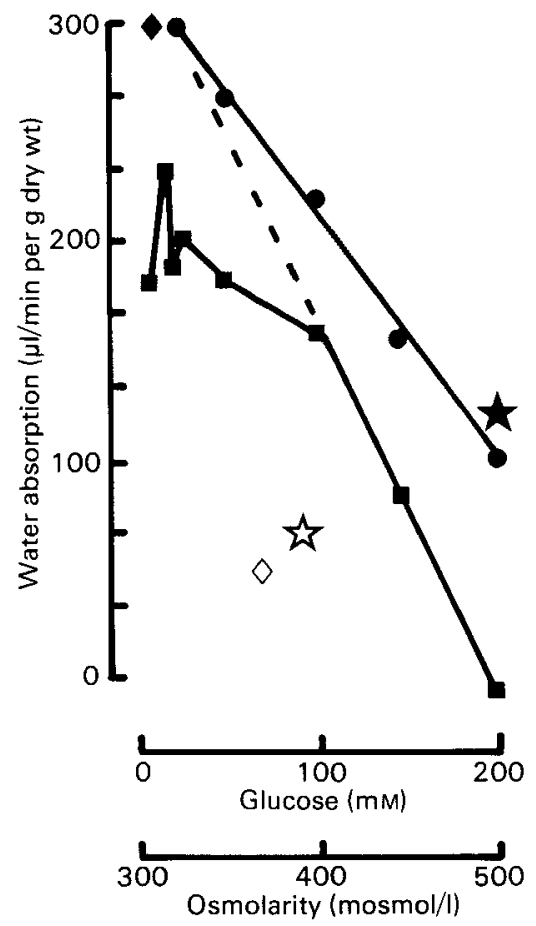

Fig. 8. Water absorption by the luminally-perfused rat small intestine in vivo. Perfusion (2 $\mathrm{ml} / \mathrm{min}$ ) was with Krebs-Henseleit bicarbonate buffer adjusted to $\mathrm{pH} \mathbf{7 . 4}$ by equilibration with air-carbon dioxide $(95: 5, \mathrm{v} / \mathrm{v})$ to which had been added, in separate experiments: (a) increasing quantities of glucose to give the hyperosmolar solutions shown ( $\square$ ), or (b) the same graded quantities of glucose from which isosmolar amounts of sodium chloride had been omitted (O). Dioralyte ${ }^{\circledR}(\star)$ and Rehidrat ${ }^{\circledR}(\lesssim)$ were made up according to the manufacturers' instructions except that the latter solution was adjusted to $\mathrm{pH} 7 \cdot 4$. The water absorption rate observed by Windmueller \& Spaeth (1980) is shown $(\diamond)$ and the water translocation rate observed by Hastewell $\&$ Parsons ( 1984$)$ is indicated $(1)$. The plot of water absorption $v$. glucose concentration over the range $100-200 \mathrm{mM}$-glucose in the hyperosomolar solutions $(400-500 \mathrm{mosmol} / \mathrm{l})$ extrapolates back to the same rate of water absorption as that given by the isosmolar solutions at low glucose concentrations (O); the reasons for the deviations from this extrapolated line when hyperosmolar solutions ( $\mathbf{D}$ ) containing $10-50 \mathrm{mM}$-glucose were used are not yet known. Each point represents a result from an intestine perfused luminally at $37^{\circ}$ for $60 \mathrm{~min}$ in a separate rat.

the osmolarity of the luminal perfusate reached $500 \mu \mathrm{osmol} / \mathrm{ml} \mathrm{did} \mathrm{the} \mathrm{intestine} \mathrm{fail}$ to absorb water and show signs of a reversed water flow (Fig. 8). Further measurements are in progress to determine the rates of translocation of ionic components from these various luminal perfusion solutions.

Companion measurements of rates of glucose absorption from these various luminal perfusates are shown in Fig. 9 (the values shown for Rehidrat do not take account of any sucrose hydrolysed and absorbed or fructose absorbed). Glucose absorption from the isosmolar solutions showed at least two marked changes in the slope of the plot of glucose absorbed $v$. initial glucose concentration in the luminal perfusate. Dioralyte (200 mM-glucose, $300 \mathrm{mosmol} / \mathrm{l}$ ) and Rehidrat (90 mM-glucose, $345 \mathrm{mosmol} / \mathrm{l}$ ) solutions gave about $50 \%$ of the rate of glucose absorption shown by the solutions of modified $\mathrm{K}-\mathrm{H}$ buffer containing the 


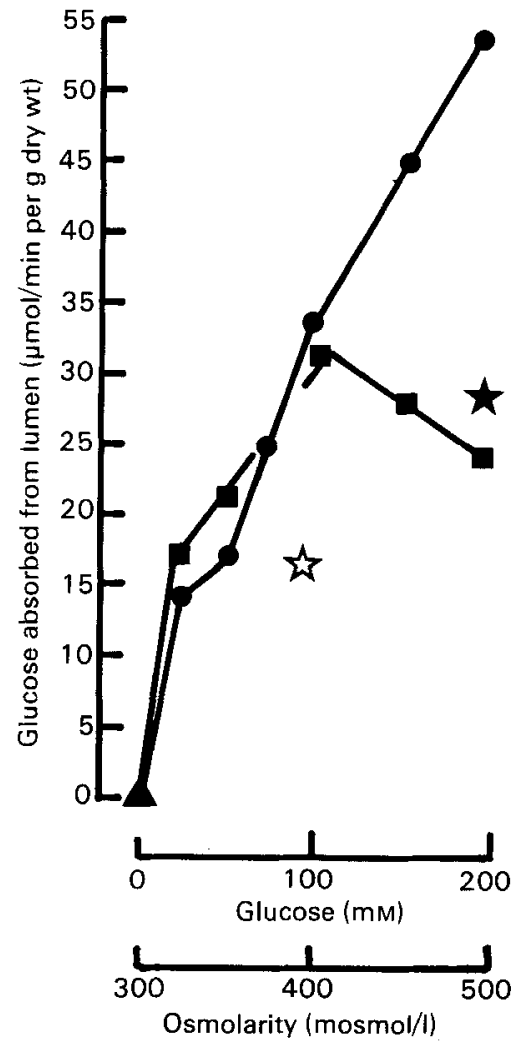

Fig. 9. Glucose absorption rates from the rat small intestine luminally perfused with isosmolar $(\theta)$ or hyperosmolar $(\boldsymbol{E})$ glucose solutions, Dioralyte ${ }^{\circledR}(\star)$ or Rehidrat ${ }^{\circledR}$ (i). The conditions of experimentation, and the perfusion media used, were those shown in Fig. 8 and used the same series of rats.

corresponding concentrations of glucose. At concentrations of glucose up to roo $\mathrm{mM}$, isosmolar and hyperosmolar luminal solutions gave very similar rates of glucose absorption (Fig. 9) but at higher initial glucose concentrations (and greater initial osmolarity) there was a sharp and linear decrease in rates of glucose absorption from the hyperosmolar solutions.

Preliminary results on total net glucose consumption (from the vascular solution containing $5 \mathrm{~mm}$-glucose and from the isosmolar lumen solutions containing I 5-200 mM-glucose) and total lactate production are shown in Fig. 10. Net glucose consumption reached a plateau rate at an initial lumen glucose concentration of between 50 and $100 \mathrm{mM}$, suggesting that either or both of the glucose-specific absorption and extraction mechanisms became saturated (probably at less than 50 mM-glucose for absorption from the lumen solution) and that, at higher lumen glucose concentrations, absorption was predominantly by diffusion; it is probably significant that, in experiments conducted in vivo (Fig. 9), absorption of glucose from isosmolar glucose solutions showed signs of saturation over the range 50-100 mm-lumen glucose. This interpretation is consistent with the observations of Murakami et al. (1977). 


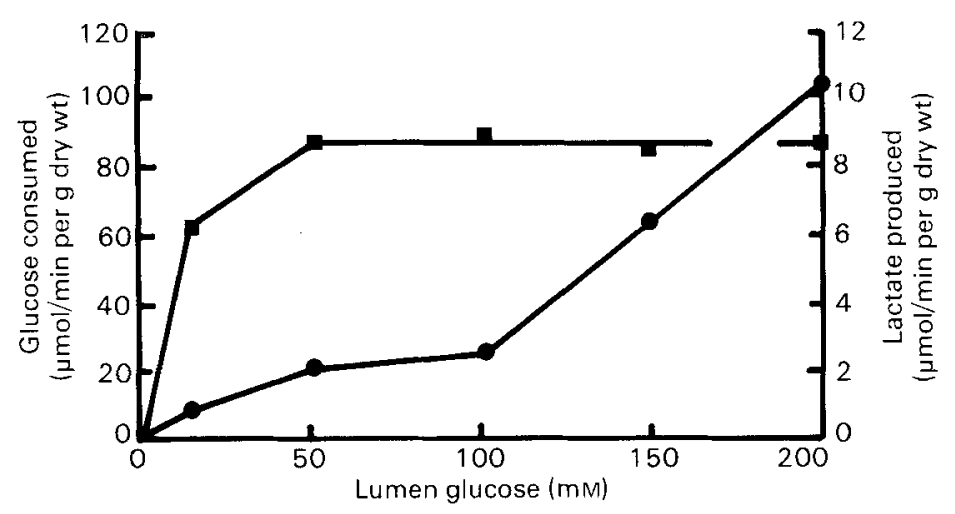

Fig. Io. Overall glucose consumption ( $)$ and lactate production $(\boldsymbol{D})$ in the luminally and vascularly perfused rat jejunum in vitro. Rat jejunum was perfused vascularly $(\mathrm{r} \cdot 4 \mathrm{ml} / \mathrm{min})$ for 60 min at $37^{\circ}$ in a recirculation system with glucose $(5 \mathrm{~mm})$ in Krebs-Henseleit bicarbonate solution (equilibrated with air-carbon dioxide $(95: 5, \mathrm{~V} / \mathrm{v})$ to $\mathrm{pH} 7 \cdot 4)$ containing 'restored' human erythrocytes (Fig. 7) to a packed cell volume of 0.40 ; dexamethasone $(250 \mathrm{ng} / \mathrm{ml})$ was added initially and noradrenalin continuously ( $100 \mathrm{ng} / \mathrm{min}$ ) throughout; arterial pressure remained steady at $70 \mathrm{~mm} \mathrm{Hg}$. The lumen was perfused simultaneously $(2 \mathrm{ml} / \mathrm{min})$ with the Krebs-Henseleit bicarbonate solution modified by replacing sodium chloride with isosmolar concentrations of glucose $(0-200 \mathrm{mM})$. Each point represents a result obtained from a separate rat.

It is significant that Murakami et al. (1977) found that the intralumen free glucose concentration in rats was as low as $2 \mathrm{~mm}$ before a meal, rose sharply during and immediately after a meal to reach a maximum of $50 \mathrm{~mm}$ for a short postprandial period, and then declined rapidly to about $15 \mathrm{~mm}$ before declining more slowly to $2 \mathrm{~mm}$ again; we used $15 \mathrm{~mm}$-glucose in the luminal perfusion medium in most of our work (Table I). Fig. Io also shows that, using an extended range of lumen glucose concentrations, net lactate production had reached a plateau at (or possibly below) an initial lumen glucose concentration of $5^{\circ} \mathrm{mm}$, suggesting that it is also possible to saturate the intracellular glycolytic pathway when the vascular glucose concentration is $5 \mathrm{~mm}$. Nicholls et al. ( 1983 ) speculated that such saturation might occur at lumen glucose concentrations in the range $20-70 \mathrm{~mm}$ used by several investigators.

It should be noted that Dioralyte and Rehidrat solutions are designed for human consumption. It would be unwise to translate the results obtained with rats directly to the human subject particularly since when taken orally the solutions would be subject to dilution by the normal secretions into the digestive tract (including oral saliva, gastric, pancreatic and biliary secretions which amount in toto to some $7-8 \mathrm{l} / \mathrm{d}$ in a normally-hydrated adult human). The results, nevertheless, indicate the utility of the perfused intestine in vivo and in vitro for testing directly the efficacy of such proprietary formulations; the perfused intestine should equally provide an appropriate and relatively-cheap test-bed for the evaluation of proposed modifications of these and other preparations intended for administration orally or by nasogastric intubation. 


\section{Conclusions}

There is convincing evidence of the potential of the perfused intestine for discovering the quantitative fate of substrates presented to this tissue either from the vascular supply or from the lumen, or from both. Some results from different laboratories show remarkable concordance although there are discrepancies which have still to be resolved. It is hoped that this review will record the initial difficulties experienced in establishing the techniques and help others who may now wish to establish this potent experimental model system for studies in nutrition. Ross (1972) has provided an invaluable guide to perfusion techniques generally.

The authors wish to record their indebtedness to Dr Dennis Parsons and Dr Paul Holloway for hospitality in their laboratory and for much helpful advice.

Work in progress in this laboratory has been supported by the Robertson Trust, the Pooled Medical Endowment Funds of the University of Aberdeen and Grampian Region Health Board.

\section{REFERENCES}

Boyd, C. A. R. \& Parsons, D. S. (1978). Fournal of Physiology (London) 274, 17-36.

Bronk, J. R. \& Ingham, P. A. (1979). Fournal of Physiology (London) 289, 99-113.

Chiba, H. \& Sasaki, R. (1978). Current Topics in Cellular Regulation 14, 76-1 16.

Davenport, H. W. (r 97r). Physiology of the Digestive Tract, $3^{\text {rd }}$ ed., pp. 28-43. Chicago: Year Book Medical Publishers Inc.

Folklow, B. \& Neil, E. (1971). Circulation, pp. 466-493. London: Oxford University Press.

Furness, J. B. \& Marshall, J. M. (1972). In 7 th European Conference on Microcirculation, part 2, pp. 404-409 [J. Ditzel and D. H. Lewis, editors]. Basel: S. Karger.

Granger, D. N. ( $198 \mathrm{I}$ ). American fournal of Physiology 240, G343-G439.

Granger, D. N., Kvietys, P. R., Mortillaroa, N. A. \& Taylor, A. E. (I980). American fournal of Physiology 239, $\mathrm{G}_{5} \mathrm{I} 6-\mathrm{G}_{523}$.

Greene, E. C. (1963). American Philosophy Society Transactions, vol. 27. London and New York: Hafner.

Hanson, P. J. \& Parsons, D. S. (1976). Fournal of Physiology (London) 255, 775-795.

Hanson, P. J. \& Parsons, D. S. (I 977). Biochemical Fournal 166, 509-519.

Hanson, P. J. \& Parsons, D. S. (I978). Fournal of Physiology (London) 278, 55-67.

Hastewell, J. G. \& Parsons, D. S. (1984). Fournal of Physiology (London) 346, 1 1 0 P.

Henrich, H. \& Biester, J. (1972). In 7 th European Conference on Microcirculation, part I, pp. 428-433. [J. Ditzel and D. H. Lewis, editors]. Basel: S. Karger.

Jodal, M. \& Lundgren, O. (1970). Acta Physiologica Scandinavica 80, 50-60.

Kosterlitz, H. W. \& Lees, G. M. (1964). Pharmacology Reviews 16, 30 I-339.

Masoro, E. J. (1973). In Physiology and Biophysics, vol. 3, pp. 65-84 [T. C. Ruch and H. D. Patton, editors]. Philadelphia: W. B. Saunders.

Morrison, A. \& Porteous, J. W. (1980). Biochemical fournal 188, 609-618.

Murakami, E., Saito, M. \& Suda, M. (1977). Experientia 33, 1469-1470.

Nicholls, T. J., Leese, H. J. \& Bronk, J. R. (1983). Biochemical fournal 212, 183-187.

Oski, F. A., Travis, S. F., Miller, L. D., Delivoria-Papodopoulos, M. \& Cannon, E. (197I). Blood $37,5^{2-} 5^{8}$.

Parsons, D. S. \& Powis, G. (1971). Fournal of Physiology (London) 2 1 7, 64 I-663.

Porteous, J. W. (1979). Environmental Health Perspectives 33, 25-35.

Porteous, J. W. (1983a). Biochemical Society Transactions II, 29-31.

Porteous, J. W. $(1983 b)$. Trends in Biochemical Science 8, 200-202. 
Porteous, J. W., Furneaux, H. M., Pearson, C. K. \& Lake, C. M. (1979). Biochemical Fournal r80, $455^{-}-463$.

Rapoport, T. M., Heinrich, R. \& Rapoport, S. M. (I976). Biochemical fournal I54, 449-469.

Rennie, M. J. \& Hollosey, J. O. (1977). Biochemical fournal 168, 16 I-1 70.

Rogausch, H. (1972). In 7th European Conference on Microcirculation, part I, pp. 128-132 [J. Ditzel and D. H. Lewis, editors]. Basel: S. Karger.

Ross, B. D. (1972). Perfusion Techniques in Biochemistry: a Laboratory Manual in the Use of Isolated Perfused Organs in Biochemical Experimentation. London: Oxford University Press.

Ruderman, N. B., Kemmer, F. W., Goodman, M. N. \& Berger, M. (1980). Biochemical fournal I90, $57-64$.

Smith, A. N. \& Brunt, P. W. (r98r). In Scientific Foundations of Surgery, 3rd ed, pp. 435-449 [J. Kyle and J. D. Hardy, editors]. London: William Heinemann Medical Books Ltd.

Tadano, K., Hellums, J. D., Lynch, E. C., Peck, E. J. \& Alfrey, C. P. (1977). Blood Cells 3, I63-I74.

Valeri, C. R. (1974). In The Red Blood Cell, and ed., pp. 528-532 [D. M. Surgenor, editor]. London and New York: Academic Press.

Volger, E., Schmid-Schönbein, H. \& Mehrishi, J. N. (1972). In 7th European Conference on Microcirculation, part I, pp. 296-302 [J. Ditzel and D. H. Lewis, editors]. Basel: S. Karger.

Weed, R. I., LaCelle, P. L. \& Merrill, E. W. (1969). Fournal of Clinical Investigation 48, 795-809.

Weinstein, R. S. (1974). In The Red Blood Cell, and ed., Pp. 213-269 [D. M. Surgenor, editor]. London and New York: Acdemic Press.

Windmueller, H. G. \& Spaeth, A. E. (1972). Fournal of Lipid Research 13, 92-105.

Windmueller, H. G. \& Spaeth, A. E. (1974). Fournal of Biological Chemistry 249, 5070-5079.

Windmueller, H. G. \& Spaeth, A. E. (1975). Archives of Biochemistry and Biophysics 171, 662-672.

Windmueller, H. G. \& Spaeth, A. E. (1976). Archives of Biochemistry and Biophysics 175, $670-676$.

Windmueller, H. G. \& Spaeth, A. E. (1977). Federation Proceedings 36, 177-181.

Windmueller, H. G. \& Spaeth, A. E. (1978). Fournal of Biological Chemistry 253, 69-76.

Windmueller, H. G. \& Spaeth, A. E. (1980). Journal of Biological Chemistry 255, 107-I 12.

Windmueller, H. G., Spaeth, A. E. \& Ganote, C. E. (1970). American Fournal of Physiology 218 , I97-204.

Wood, J. D. (1981). Annual Review of Physiology 43, 33-5 I. 